\title{
Angiotensina-(1-7) durante o processo inicial na cascata da ovulação em bovinos
}

\author{
Angiotensin-(1-7) during the initial process of ovulatory cascade in cattle
}

\author{
Joabel Tonellotto dos Santos ${ }^{I}$ Bernardo Garziera Gasperin $^{I^{*}}$ Vitor Braga Rissi $^{\mathrm{I}}$ \\ Matheus Pedrotti De Cesaro ${ }^{I}$ Alfredo Skrebsky Cezar ${ }^{I}$ João Francisco Coelho de Oliveira ${ }^{\mathrm{I}}$ \\ Paulo Bayard Dias Gonçalves ${ }^{\mathrm{I}}$
}

\section{RESUMO}

O presente estudo teve como objetivo avaliar o efeito da Ang-(1-7) e de seu receptor (MAS) na regulação da ovulação. No experimento I, utilizando um modelo in vitro de cultivo de células foliculares, foi avaliado o efeito do tratamento com Ang-(1-7) ou do bloqueio do receptor MAS através do inibidor d-Ala7-Ang-(1-7) (A-779) na expressão de RNAm para epirregulina (Ereg; um marcador inicial do processo de ovulação) em células da granulosa. No experimento II, foi utilizado um modelo in vivo de injeção intrafolicular no qual vinte vacas tiveram o ciclo estral sincronizado e, quando os folículos atingiram um diâmetro mínimo de $12 \mathrm{~mm}$, foi realizada a injeção intrafolicular de A-779 ou solução salina $0,9 \%$. No momento da injeção intrafolicular, foi realizada uma aplicação IM de análogo de GnRH. A suplementação com Ang-(1-7) ou o bloqueio de seu receptor MAS em sistema de cultivo de células da granulosa não alteraram o padrão de expressão de RNAm para Ereg. A aplicação intrafolicular de A-779 $\left(10^{-5} \mathrm{M}\right)$ não bloqueou a ovulação quando realizada antes do início do pico esperado de LH (100\% das vacas ovularam nos grupos A-779 e controle), sugerindo que a Ang(1-7) não possui papel relevante no início da cascata ovulatória em bovinos.

Palavras-chave: angiotensina (1-7), ovulação, receptor MAS, ECA2, bovino.

\section{ABSTRACT}

This study aimed to evaluate the effect of Ang-(17) and its receptor (MAS) in the regulation of the ovulatory cascade. In the experiment I, the effect of Ang-(1-7) or d-Ala7Ang-(1-7) (A-779; Ang-(1-7) antagonist) on the epirregulin (Ereg; initial marker of ovulation process) mRNA expression in granulosa cells was assessed using an in vitro model of follicular cell culture. In experiment II, it was used an in vivo

\begin{abstract}
intrafollicular injection model, in which twenty cows had their follicular waves synchronized and the ovarian follicular size was daily monitored by ultrasound. Follicles that reached a minimum diameter of $12 \mathrm{~mm}$ were injected with A-779 or saline $0.9 \%$. At the time of the intrafollicular injection, cows were challenged with an intramuscular application of GnRH analogue. Ang-(1-7) or the blockade of its receptor MAS had no effect in Ereg mRNA expression in granulosa cells cultured in vitro. Likewise, the intrafollicular injection of MAS receptor inhibitor $\left(10^{-5} \mathrm{M}\right.$ of A-779) did not block ovulation before the expected time of LH peak (100\% of the cows ovulated after GnRH challenge in the treatment and control groups), suggesting that Ang-(1-7) has no role in the early ovulatory cascade in cattle.
\end{abstract}

Key words: angiotensin (1-7), ovulation, MAS receptor, $A C E_{2}$, bovine.

\section{INTRODUÇÃO}

Nas últimas décadas, uma série de fatores de crescimento e peptídeos regulatórios foram identificados como reguladores do crescimento folicular, ovulação e luteinização (YOSHIMURA, 1997; RICHARDS et al., 2002). Nesse sentido, alguns modelos de sinalização para o desencadeamento da ovulação têm sido propostos para mamíferos, a partir do pico ovulatório de gonadotrofina (BRIDGES et al., 2006; FORTUNE et al., 2009). Os modelos mais estudados e aceitos são aqueles que envolvem os fatores de crescimento semelhantes ao EGF (Epidermal Growth Factor) como a ampirregulina (Areg) e a epirregulina (Ereg), os quais são induzidos pelo pico

'Laboratório de Biotecnologia e Reprodução Animal (BioRep), Universidade Federal de Santa Maria (UFSM), Hospital Veterinário, 97105-900, Santa Maria, RS, Brasil. E-mail: bggasperin@gmail.com.*Autor para correspondência 
de LHe estimulam a síntese de PTGS2 (Prostaglandinendoperoxide synthase 2), iniciando os processos de proteólise e remodelação tecidual (PARK et al., 2004). Apesar de vários fatores terem sido descobertos através desses modelos, a complexa interação entre fatores locais e rotas intracelulares reguladas entre o pico de gonadotrofina e o rompimento do folículo com liberação do oócito maturo capaz de ser fecundado ainda é desconhecida. Entre os sistemas locais atuantes nesses processos, destaca-se o sistema renina-angiotensina (SRA), através de seus peptídeos com funções já bem estabelecidas na ovulação (FERREIRA et al., 2007) e maturação de oócitos (BARRETA et al., 2008).

No processo de ovulação, entre os componentes do SRA, a angiotensina II (Ang II) tem sido amplamente estudada. Em bovinos, a Ang II é indispensável nos momentos iniciais da cascata ovulatória induzida pelo LH (FERREIRA et al., 2007), além de possuir uma função vasoativa importante para a formação e regressão do corpo lúteo (ACOSTA \& MIYAMOTO, 2004). A regulação dos componentes do sistema Ang II demonstra a participação deles durante a ovulação; no entanto, a Ang II não é o único peptídeo ativo do SRA. Outros peptídeos gerados a partir da Ang Ie Ang II, como a Ang-(1-7) (FELIX et al., 1991), também podem mediar as ações do SRA em diferentes processos fisiológicos (COSTA et al., 2003; SAMPAIO et al., 2007).

AAng-(1-7) é o ligante para o receptor MAS (SANTOS et al., 2003) e suas ações são especificamente inibidas quando o receptor MAS é bloqueado com dAla7-Ang-(1-7), também conhecido como A-779 (DILAURO \& BURNS, 2009). A expressão de RNAm para MAS foi verificada em vários tecidos, incluindo ovários de roedores e bovinos (COSTA et al., 2003; SANTOS et al., 2011) e testículos de ratos e homens (METZGER et al., 1995; REIS et al., 2010). No entanto, pouco se sabe sobre a possível função ou via de ação da Ang-(1-7) na ovulação.

Em ratas, os níveis ovarianos de Ang-(1-7) estão mais elevados no proestro e estro, quando comparados aos níveis do metaestro e diestro (COSTA et al., 2003). Os mesmos autores demonstraram que Ang-(1-7) induz um aumento nas concentrações de estradiol e progesterona, sendo esse efeito inibido por A-779. Isso demonstra que a Ang-(1-7) utiliza receptor específico para atuar na esteroidogênese em roedores. A localização da Ang-(1-7) e do receptor MAS nas células intersticiais e tecais de folículos antrais e préovulatórios de ratas tratadas com eCG também já foram observadas (COSTA et al., 2003; PEREIRA et al., 2009). Foi também demonstrado que a expressão de RNAm para MAS e para a enzima conversora de angiotensina $2\left(\mathrm{ECA}_{2}\right)$, responsável pela clivagem de Ang II em Ang-
(1-7), aumenta em homogenatos de ovário de ratas tratadas com eCG (PEREIRA et al., 2009). Isso sugere uma possível função da Ang-(1-7) a partir de um estímulo por gonadotrofina.

Apesar de resultados apontarem uma possível ação e regulação da Ang-(1-7) na função ovariana, pouco se sabe até o momento em relação a sua função em espécies monovulares, como a bovina. Para tanto, testou-se a hipótese de que a Ang-(1-7) é um mediador necessário durante o processo ovulatório em bovinos, regulando a expressão de epirregulina. $\mathrm{O}$ objetivo deste estudo foi detectar a proteína do receptor MAS e avaliar o efeito da Ang-(1-7) sobre a expressão de RNAm para Ereg nas células da granulosa bovina. Além disso, o efeito do bloqueio do receptor MAS sobre a expressão de Ereg, induzida por LH in vitro, e sobre a taxa de ovulação induzida por $\mathrm{GnRH}$ in vivo, também foi avaliado.

\section{MATERIAL E MÉTODOS}

\section{Experimento I}

Identificação do receptor MAS em células da granulosa bovina

Ovários bovinos foram obtidos imediatamente após o abate e transportados para o laboratório em solução salina a $30^{\circ} \mathrm{C}$. A proteína total de um fragmento ovariano (contendo tecido cortical e medular) e células da granulosa provenientes de folículo bovino com $15 \mathrm{~mm}$ de diâmetro (cujo par não possuía corpo lúteo) foram extraídas utilizando o buffer M-PER (Thermo Scientific, USA) e quantificadas usando NanoDrop (Thermo Scientific, USA). Após desnaturação a $95^{\circ} \mathrm{C}, 25 \mu \mathrm{g}$ de cada amostra foi submetida a um gel de SDS a $10 \%$ e eletro-transferidas para uma membrana de nitrocelulose. Após bloqueio por $2 \mathrm{~h}$ com leite desnatado a 5\% em PBS contendo $0.1 \%$ tween-20 (PBS-T), a membrana foi incubada overnight a $4^{\circ} \mathrm{C}$ com anticorpo de coelho anti-MAS humano na diluição de 1:200 (sc135063; Santa Cruz Biotechnology Inc., CA, USA) em agitação. Após três lavagens (10 min cada) com PBS-T, a membrana foi incubada com anticorpo secundário caprino anti-IgG de coelho (ab6721; Abcam Inc., USA) na diluição de 1:5000 por $2 \mathrm{~h}$ em agitação, seguido por três lavagens. Finalmente, as membranas foram incubadas com substrato Lumi-Light PLUS (Roche, USA) por 3 min e visualizadas usando o Chemidoc analyser (BioRad, CA, USA).

\section{Cultivo de células foliculares}

Foi usado um sistema de cultivo de células de folículos $\geq 12 \mathrm{~mm}$ como modelo experimental semelhante ao descrito por BRIDGES 
et al. (2006), com modificações. Brevemente, pares de ovários bovinos que não apresentavam corpo lúteo foram obtidos em abatedouro, imediatamente após o abate, e transportados para o laboratório em solução salina a $30^{\circ} \mathrm{C}$. O tempo total decorrido durante a coleta dos ovários e o início do cultivo foi de cerca de $2 \mathrm{~h}$. A partir de cada par de ovários, foi feita a dissecação do folículo com diâmetro pré-ovulatório $\geq 12 \mathrm{~mm}$. Os fragmentos foliculares contendo teca e granulosa foram cortados em porções de aproximadamente $2-3 \mathrm{~mm}^{3}$, as quais foram cuidadosamente lavadas em meio MEM (Sigma Aldrich, USA) suplementado com 50UI ml ${ }^{-1} \mathrm{de}$ penicilina (Sigma Aldrich, USA) e $50 \mu \mathrm{g} \mathrm{ml}^{-1}$ de estreptomicina (Sigma Aldrich, USA) a $37^{\circ} \mathrm{C}$. Os fragmentos foram distribuídos aleatoriamente em placas de quatro poços em número de quatro fragmentos/poço com $400 \mu$ de meio de cultivo em que receberam os tratamentos.

Os fragmentos foliculares foram cultivados na presença ou ausência de LH $\left(100 \mathrm{ng} \mathrm{ml}^{-1}\right)$ e diferentes concentrações de Ang-(1-7) (Sigma Aldrich, USA) e inibidor A-779 (Sigma Aldrich, USA), constituindo os seguintes grupos: células foliculares (controle negativo); células foliculares + LH (controle positivo); células foliculares + Ang-(1-7) $10^{-5} \mathrm{M}$; células foliculares +Ang-(1-7) 10-7 M; células foliculares Ang-(1-7) 10-9 M; células foliculares $+\mathrm{LH}+\mathrm{A}-77910^{-5} \mathrm{M}$; células foliculares + LH + A-779 $10^{-7} \mathrm{M}$; células foliculares + $\mathrm{LH}+\mathrm{A}-77910^{-9} \mathrm{M}$. As concentrações utilizadas foram baseadas nas concentrações fisiológicas de Ang-(1-7) encontradas por SANTOS et al. (2011). Após 3h de cultivo, as células da granulosa foram coletadas através de sucessivas pipetagens no meio de cultivo, fazendo com que as células se desprendessem dos fragmentos. $\mathrm{Na}$ sequência, o meio foi centrifugado e as células da granulosa recuperadas e congeladas a $-80^{\circ} \mathrm{C}$ para extração de RNAm.

\section{Extração de RNA, transcrição reversa e qPCR}

O RNA total foi extraído usando Trizol (Invitrogen, Brasil) de acordo com as recomendações do fabricante. A quantificação de RNA e a verificação de contaminação foram realizadas conforme SANTOS et al. (2011), utilizando o NanoDrop (Thermo Scientific, USA). A integridade do RNA foi verificada submetendo $1 \mu \mathrm{g}$ de RNA de cada amostra, $3 \mu$ l de loading buffer (Sigma Aldrich, USA) e $2 \mu l$ de água ultra pura a $70^{\circ} \mathrm{C}$ por $5 \mathrm{~min}$. Após, foi realizada eletroforese em gel de agarose 1,2\% para a visualização das bandas de RNA ribossomal (RNAr). $A$ presença de rastros abaixo das bandas referentes às porções 28S e 18S do RNAr indica degradação.

O RNA total foi tratado com DNase (Invitrogen, Brasil) a $37^{\circ} \mathrm{C}$ por $30 \mathrm{~min}$ para digerir DNA genômico contaminante. A reação de transcrição reversa foi realizada com $1 \mathrm{mM}$ oligo (dT) primer, Omniscript (Qiagen, Mississauga, ON, Canada) RTased, dNTP's e inibidor da RNase(Amersham Biosciences, CA, USA). A expressão relativa dos genes foi realizada por PCR em tempo real (Step One Plus, Applied Byossistems) com Power SYBR Green PCR Master Mix (Applied Biosystems, USA). As análises de expressão foram realizadas conforme SANTOS et al. (2011). As sequências dos primers para Ereg (iniciador sense: ACTGCACAGCATTAGTTCAAACTGA; iniciador anti-sense: TGTCCATGCAAACAGTAGCCATT) e ciclofilina (SANTOS et al., 2011) foram obtidas utilizando Primer Express Software v3.0 (Applied Biosystems, USA) e sintetizados pela Invitrogen. O experimento foi realizado em três replicações para cada grupo experimental.

\section{Experimento II}

Animais, injeção intrafolicular e dinâmica folicular

Vinte vacas adultas cíclicas não lactantes das raças Hereford e Red Angus com condição corporal $\geq 3$ (1-5) e peso de aproximadamente $450 \mathrm{~kg}$ tiveram uma nova onda folicular induzida. Brevemente, no dia 0 do protocolo, foram realizadas duas aplicações de cloprostenol sódico (PGF2alfa, Ourofino, Brasil) com intervalo de 12 horas, totalizando $500 \mu \mathrm{g}$ (IM), $2 \mathrm{mg}$ de benzoato de estradiol (BE) e um implante intravaginal de progesterona (DIB; 1g; Intervet/Schering-Plough, Brasil), o qual permaneceu por nove dias. Os animais nos quais o maior folículo em crescimento que atingiu diâmetro $\geq 12 \mathrm{~mm}$ receberam GnRH ( $100 \mu \mathrm{g}$ de acetato de gonadorelina, IM; Tortuga, Brasil) e foram aleatoriamente distribuídos para receberem injeção intrafolicular de $10^{-5} \mathrm{M}$ de A-779 (grupo A-779), bloqueador do receptor de Ang-(1-7), ou solução salina 0,9\% (grupo controle).

As injeções intrafoliculares foram guiadas por ultrassom (Aquila Vet, Pie Medical Equipment BV, Holanda) equipado com uma sonda convexa de 7,5MHz. Para a aplicação dos tratamentos no folículo-alvo, foi utilizado um sistema de duas vias acoplado a uma guia de biopsia, conforme descrito por FERREIRA et al. (2007). Após a aplicação dos tratamentos, foi realizado monitoramento ultrassonográfico a cada $24 \mathrm{~h}$. A ovulação foi caracterizada quando se observou o desaparecimento do folículo tratado entre duas avaliações e, posteriormente, a formação do corpo lúteo.

\section{Análise estatística}

Os resultados de expressão gênica foram comparados por análise de variância (PROC GLM; General Linear Models Procedure). Quando verificado 
efeito do tratamento, as médias entre os grupos foram comparadas utilizando o teste de multi-comparação de médias (LSMEANS). As expressões de RNAm foram testadas para normalidade com o auxílio do teste de Shapiro-Wilk e normalizadas, quando necessário, de acordo com cada distribuição. Os resultados dos índices de ovulações não foram avaliados por testes estatísticos no experimento II, em decorrência de ter sido obtido $100 \%$ de ovulação nos dois grupos. As análises foram realizadas utilizando o programa estatístico SAS (SAS Institute Inc., Cary, NC, USA) e os resultados estão representados como média \pm erro padrão da média.

\section{RESULTADOS}

Experimento I

A proteína do receptor MAS (aproximadamente 30kDa; Figura 1A) foi detectada em fragmento de ovário bovino e células da granulosa isoladas de folículo $>12 \mathrm{~mm}$ (para Western blot, o folículo apresentou um tamanho de $15 \mathrm{~mm}$ ). AAng-(1-7) nas doses utilizadas não alterou o padrão de expressão de RNAm para Ereg (Figura 1B) nas células da granulosa, quando estas foram cultivadas na ausência de LH. O A-779 também não alterou o padrão de expressão de RNAm de Ereg (Figura 1C) no cultivo celular suplementado com LH.

\section{Experimento II}

Nove das vinte vacas foram utilizadas, sendo os outros animais descartados do estudo por não apresentarem diâmetro folicular esperado ( $\geq 12 \mathrm{~mm})$. Os nove animais foram distribuídos aleatoriamente nos grupos A-779 $(n=5)$ e controle $(n=4)$. Todos os animais de ambos os grupos ovularam entre 24 e $48 \mathrm{~h}$ após a injeção intrafolicular.

\section{DISCUSSÃO}

Os principais achados deste estudo são: 1) a proteína do receptor MAS está presente no ovário bovino e nas células da granulosa de folículo préovulatório; 2) no cultivo in vitro, as doses utilizadas de Ang-(1-7) não foram capazes de regular positivamente a expressão de RNAm de Ereg; 3) no cultivo in vitro, o A-779 não reduziu a expressão de RNAm de Ereg e; 4) a injeção intrafolicular de A-779

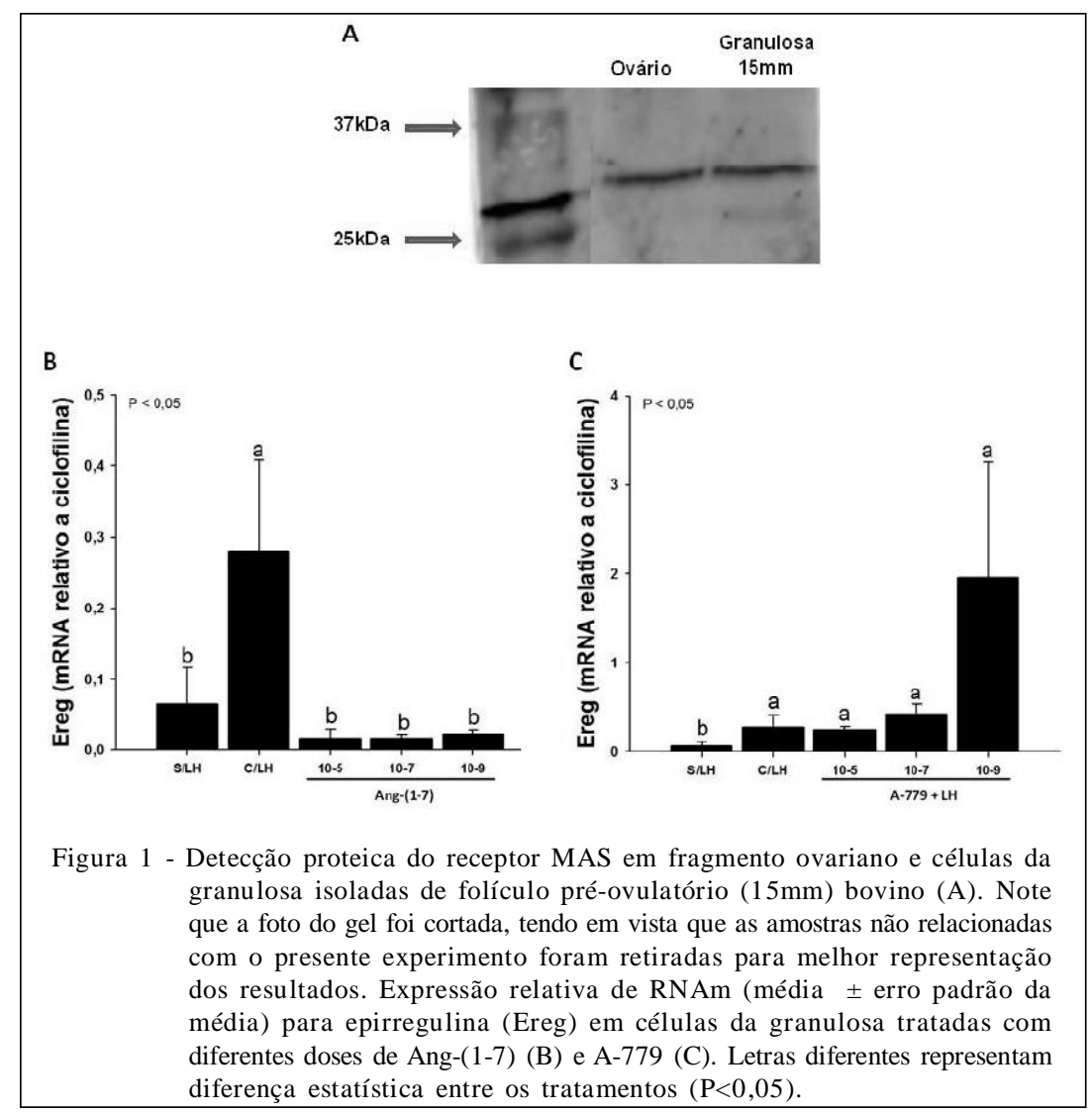

Ciência Rural, v.42, n.10, out, 2012. 
$\left(10^{-5} \mathrm{M}\right)$ não foi capaz de bloquear a ovulação em bovinos. Esses resultados sugerem que, ao contrário da Ang II (KUJI et al., 1996; FERREIRA et al., 2007), a Ang-(1-7) parece não ser necessária, nem essencial para desencadear o processo de ovulação em bovinos.

Recentemente, este grupo de estudos demonstrou a presença da Ang-(1-7) no líquido folicular e expressão de RNAm para o receptor MAS e para as enzimas que dão origem a Ang-(1-7) através da clivagem de AngI e Ang II em folículos pré-ovulatórios bovinos (SANTOS et al., 2011). Em humanos, a Ang-(1-7) está presente no líquido folicular e a presença do seu receptor MAS foi detectada no ovário (REIS et al., 2010). Adicionalmente, em ratos, a expressão de RNAm para o receptor MAS, em homogenatos de ovário é regulada positivamente por eCG (PEREIRA et al., 2009). No presente estudo, usando o bovino como modelo para experimentos in vivo, não foram observados efeitos sobre a ovulação quando o receptor da Ang-(1-7) foi bloqueado. O estímulo com Ang-(1-7) ou bloqueio de seu receptor no cultivo in vitro de fragmentos de folículos pré-ovulatórios não alterou a expressão de Ereg, um marcador inicial na cascata da ovulação.

Apesar da detecção do produto proteico do receptor MAS nas células da granulosa bovina, o bloqueio do receptor da Ang-(1-7) in vivo não foi efetivo para bloquear a ovulação em bovinos, ao contrário do que acontece com o bloqueio dos receptores para Ang II (FERREIRA et al., 2007). O bloqueio dos receptores de Ang II só foi efetivo em períodos iniciais do processo de ovulação, até $6 \mathrm{~h}$ após o desafio com GnRH (FERREIRA et al., 2007). No entanto, um estudo recente indica que as concentrações intrafoliculares de Ang-(1-7) só aumentam 24h após a aplicação de GnRH (SANTOS et al., 2011). As doses utilizadas de Ang-(1-7) (in vitro) e A-779 (in vivo e in vitro) foram similares ou superiores à concentração fisiológica de Ang-(1-7), encontrada no líquido folicular bovino (SANTOS et al., 2011). A perfusão cardíaca de Ang-(1-7) em camundongos produz efeitos vasculares complexos que envolvem a interação de seu receptor e dos receptores de Ang II, levando à liberação de prostaglandinas e óxido nítrico (CASTRO et al., 2005). Também, em cultivo de células endoteliais humanas, a Ang-(1-7) é capaz de estimular a liberação de prostaglandinas e óxido nítrico (SAMPAIO et al., 2007), importantes para o mecanismo final da ovulação. É possível que a Ang-(1-7) atue nos instantes finais da ovulação relacionados com a ruptura do folículo e luteinização, visto que neste estudo, ao contrário do que ocorre com Ang II (PORTELA et al., 2011), não foi observado efeito da Ang-(1-7) sobre Ereg, importante marcador de eventos iniciais do processo ovulatório.
Nesse sentido, cultivos in vitro com suplementação de tratamentos por um maior período podem agregar conhecimentos sobre um possível papel da Ang-(1-7) nesses eventos, podendo-se utilizar uma molécula ativada pela ligação Ang(1-7)/MAS. Entretanto, devese considerar que a Ang-(1-7) é um peptídeo derivado da clivagem da Ang II (FELIX et al., 1991) e pode não possuir uma ação direta no processo de ovulação em bovinos, contrariando os dados obtidos em espécies de ovulação múltipla.

VIANA et al. (2011), utilizando um modelo de perfusão de ovários de coelhas, demonstraram que a Ang-(1-7) é capaz de induzir a ovulação e produção de estradiol na ausência de gonadotrofinas. Além disso, o bloqueio de seu receptor foi capaz de inibir o efeito das gonadotrofinas na ovulação. Neste estudo, não foi possível evidenciar um papel relevante da Ang-(17) durante os momentos iniciais da cascata da ovulação. No entanto, considerando que o antagonista da Ang(1-7) (SANTOS et al., 1994) foi injetado no início do processo de ovulação (simultaneamente com a aplicação de GnRH), não pode ser excluído um efeito mais tardio.

\section{CONCLUSÃO}

AAng-(1-7) e o inibidor A-779, quando em cultivo in vitro por 3 horas, não são capazes de regular a expressão de Ereg. A injeção intrafolicular na concentração de $10^{-5} \mathrm{M}$ de A-779 não inibe o processo ovulatório, indicando que a Ang-(1-7) não possui papel relevante no início da cascata ovulatória em bovinos.

\section{COMITÊ DE ÉTICA E BIOSSEGURANÇA}

Processo no $23081.004717 / 2010-53$.

\section{REFERÊNCIAS}

ACOSTA, T.J.; MIYAMOTO, A. Vascular control of ovarian function: ovulation, corpus luteum formation and regression. Anim Reprod Sci, v.82-83, p.127-140, 2004. Disponível em: <http://www.ncbi.nlm.nih.gov/ entrez/query.fcgi $? \mathrm{cmd}=$ Retrieve $\& \mathrm{db}=\mathrm{PubMed} \& \mathrm{dopt}=\mathrm{Citation} \&$ list_uids $=15271448>$. Acesso em: 28 out. 2010. doi: 10.1016/ j.anireprosci.2004.04.022S0378432004000697[pii].

BARRETA, M.H. et al. Evidence that the effect of angiotensin II on bovine oocyte nuclear maturation is mediated by prostaglandins E2 and F2alpha. Reproduction, v.136, n.6, p.733-740, 2008. Disponível em: <http://www.reproductiononline.org/cgi/reprint/136/6/733.pdf>. Acesso em: 28 out. 2010. doi: REP-08-0268 [pii]10.1530/REP-08-0268.

BRIDGES, P.J. et al. Gonadotropin-induced expression of messenger ribonucleic acid for cyclooxygenase- 2 and production of prostaglandins E and F2alpha in bovine preovulatory follicles are regulated by the progesterone receptor. Endocrinology, 
v.147, n.10, p.4713-4722, 2006. Disponível em: <http:// endo.endojournals.org/cgi/reprint/147/10/4713.pdf $>$. Acesso em: 28 out. 2010. doi: en.2005-1575[pii]10.1210/en.2005-1575.

CASTRO, C.H. et al. Evidence for a functional interaction of the angiotensin-(1-7) receptor Mas with AT1 and AT2 receptors in the mouse heart. Hypertension, v.46, n.4, p.937-942, 2005. Disponível em: 〈http://hyper.ahajournals.org/cgi/reprint/46/4/937.pdf>. Acesso em: 28 out. 2010. doi: 01.HYP.0000175813.04375.8a[pii]10.1161/ 01.HYP.0000175813.04375.8a.

COSTA, A.P. et al. Angiotensin-(1-7): a novel peptide in the ovary. Endocrinology, v.144, n.5, p.1942-1948, 2003. Disponível em: <http://endo.endojournals.org/cgi/reprint/144/5/1942.pdf>. Acesso em: 28 out. 2010 . doi: 10.1210/en.2002-220787.

DILAURO, M.; BURNS, K.D. Angiotensin-(1-7) and its effects in the kidney. Scientific World Journal, v.9, p.522-535, 2009. Disponível em: <http://www.ncbi.nlm.nih.gov/entrez/ query.fcgi $? \mathrm{cmd}=$ Retrieve $\& \mathrm{db}=$ PubMed $\&$ dopt $=$ Citation $\&$ list_uids $=19578709>$. Acesso em: 28 out. 2010 . doi: $10.1100 /$ tsw. 2009.70 .

FELIX, D. et al. Neurophysiological responses to angiotensin(1-7). Hypertension, v.17, n.6 Pt.2, p.1111-1114, 1991. Disponível em: <http://www.ncbi.nlm.nih.gov/entrez/ query.fcgi cmd $=$ Retrieve $\& \mathrm{db}=$ PubMed $\&$ dopt $=$ Citation $\&$ list_uids $=2045157>$. Acesso em: 28 out. 2010. doi. 10.1161/ 01.HYP.17.6.1111

FERREIRA, R. et al. The role of angiotensin II in the early stages of bovine ovulation. Reproduction, v.134, n.5, p.713719, 2007. Disponível em: <http://www.reproductiononline.org/cgi/reprint/134/5/713.pdf>. Acesso em: 28 out. 2010. doi: 134/5/713[pii]10.1530/REP-07-0239.

FORTUNE, J.E. et al. The periovulatory period in cattle: progesterone, prostaglandins, oxytocin and ADAMTS proteases. Anim Reprod, v.6, n.1, p.60-71, 2009. Disponível em: <http://www.ncbi.nlm.nih.gov/ entrez/query.fcgi? $\mathrm{cmd}=\mathrm{Retrieve} \& \mathrm{db}=\mathrm{PubMed} \& \mathrm{dopt}=$ Citation\&list_uids=20390049>. Acesso em: 28 out. 2010 .

KUJI, N. et al. Involvement of angiotensin II in the process of gonadotropin-induced ovulation in rabbits. Biol Reprod, v.55, n.5, p.984-991, 1996. Disponível em: <http://www.ncbi.nlm.nih.gov/ entrez/query.fcgi ? cmd $=$ Retrieve $\& d b=P u b M e d \&$ dopt=Citation\&list_uids=8902207>. Acesso em: 28 out. 2010. doi. 10.1095/?biolreprod55.5.984

METZGER, R. et al. Expression of the mouse and rat mas protooncogene in the brain and peripheral tissues. FEBS Lett, v.357, n.1, p.27-32, 1995. Disponível em: <http://www.ncbi.nlm.nih.gov/ entrez/query.fcgi cmd=Retrieve $\& d b=$ PubMed $\&$ dopt $=$ Citation $\&$ list_uids $=8001672>$. Acesso em: 28 out. 2010. doi: 00145793(94)01292-9 [pii].

PARK, J.Y. et al. EGF-like growth factors as mediators of LH action in the ovulatory follicle. Science, v.303, n.5658, p.682-684, 2004. Disponível em: <http://www.sciencemag.org/ content/303/5658/682.full.pdf $>$. Acesso em: 28 out. 2010 doi: 10.1126/science. 10924631092463 [pii].

PEREIRA, V.M. et al. Gonadotropin stimulation increases the expression of angiotensin- $(1-7)$ and MAS receptor in the rat ovary. Reprod Sci, v.16, n.12, p.1165-1174, 2009. Disponível e m: <ht t p ://www.ncbi.nl m.nih.gov/entrez/ query.fcgi $? \mathrm{cmd}=$ Retrieve $\& \mathrm{db}=\mathrm{PubMed} \& \mathrm{dopt}=$ Citation \&list_uids $=19703990>$. Acesso em: 28 out. 2010 . doi: 1933719109343309 [pii]10.1177/1933719109343309.

PORTELA, V.M. et al. Role of Angiotensin II in the periovulatory epidermal growth factor-like cascade in bovine granulosa cells in vitro. Biol Reprod, v.85, n.6, p.1167-1164, 2011. Disponível em: <http://www.biolreprod.org/content/early/2011/08/17/ biolreprod.111.094193.full.pdf $>$. Acesso em: 28 out. 2010. doi: biolreprod.111.094193[pii]10.1095/biolreprod.111.094193.

REIS, A.B. et al. Angiotensin (1-7) and its receptor Mas are expressed in the human testis: implications for male infertility. J Mol Histol, v.41, n.1, p.75-80, 2010. Disponível em: <http://www.ncbi.nlm.nih.gov/ entrez/query.fcgi ? $\mathrm{cmd}=$ Retrieve $\& \mathrm{db}=\mathrm{PubMed} \& \mathrm{dopt}=$ Citation\&list_uids=20361351>. Acesso em: 28 out. 2010. doi: 10.1007/ s10735-010-9264-8.

RICHARDS, J.S. et al. Novel signaling pathways that control ovarian follicular development, ovulation, and luteinization. Recent Prog Horm Res, v.57, p.195-220, 2002. Disponível em: <http://www.ncbi.nlm.nih.gov/ entrez/query.fcgi cmd $=$ Retrieve $\& d \mathrm{~b}=\mathrm{PubMed} \& \mathrm{dopt}=$ Citation\&list_uids=12017544>. Acesso em: 28 out. 2010.

SAMPAIO, W.O. et al. Angiotensin-(1-7) through receptor Mas mediates endothelial nitric oxide synthase activation via Akt-dependent pathways. Hypertension, v.49, n.1, p.185192, 2007. Disponível em: <http://hyper.ahajournals.org/cgi/ reprint/49/1/185.pdf $>$. Acesso em: 28 out. 2010 . doi: 01.HYP.0000251865.35728.2f [pii]10.1161.

SANTOS, R.A. et al. Characterization of a new angiotensin antagonist selective for angiotensin-(1-7): evidence that the actions of angiotensin-(1-7) are mediated by specific angiotensin receptors. Brain Res Bull, v.35, n.4, p.293-298, 1994. Disponível em: <http://www.ncbi.nlm.nih.gov/entrez/ query.fcgi? $\mathrm{cmd}=$ Retrieve $\& \mathrm{db}=$ PubMed $\& d o p t=$ Citation $\&$ list_uids $=$ 7850477>. Acesso em: 28 out. 2010.

SANTOS, R.A. et al. Angiotensin-(1-7) is an endogenous ligand for the G protein-coupled receptor Mas. Proc Natl Acad Sci U S A, v.100, n.14, p.8258-8263, 2003. Disponível em: <http:/ /www.pnas.org/content/100/14/8258.full.pdf>. Acesso em: 28 out. 2010. doi: 10.1073/pnas.14328691001432869100 [pii].

SANTOS, J. et al. Molecular characterization and regulation of the angiotensin-converting enzyme type 2/Angiotensin-(1-7)/ MAS receptor axis during the ovulation process in cattle. $\mathbf{J}$ Renin Ang Ald Syst, v.13, n.1, p.1-8, 2012. Disponível em: <http://jra.sagepub.com/content/early/2011/08/03/ 1470320311417273.full.pdf $>$. Acesso em: 28 out. 2011. doi: 1470320311417273 [pii] $10.1177 / 1470320311417273$.

VIANA, G.E. et al. Angiotensin-(1-7) induces ovulation and steroidogenesis in perfused rabbit ovaries. Exp Physiol, v.96, n.9, p.957-965, 2011. Disponível em: <http://ep.physoc.org/ content/96/9/957.full.pdf $>$. Acesso em: 28 out. 2010. doi: expphysiol.2011.058453 [pii] 10.1113 .

YOSHIMURA, Y. The ovarian renin-angiotensin system in reproductive physiology. Front Neuroendocrinol, v.18, n.3, p.247-291, 1997. Disponível em: <http://www.ncbi.nlm.nih.gov/ entrez/query.fcgi?cmd=Retrieve $\& \mathrm{db}=\mathrm{PubMed} \& \mathrm{dopt}=$ Citation $\&$ list_uids $=9237079>$. Acesso em: 28 out. 2010 . doi: S00913022(97)90152-7 [pii]. 